\title{
Variables in the effect of land use on soil extrapore enzymatic activity and carbon stabilization
}

\author{
Melanie M. Glenn (1D) ${ }^{1 凶}$
}

ARISING FRom Kravchenko et al. Nature Communications https://doi.org/10.1038/s41467-019-11057-4

T he recent study by Kravchenko et al. ${ }^{1}$ that was published in Nature Communications explores the relationship between microbial spatial footprints and soil carbon (C) storage capacity. The authors concluded that plant-stimulated soil pore formation is a major determinant of soil $\mathrm{C}$ sequestration rates, that diverse plant communities favor the development of $30-150 \mu \mathrm{m}$ pores, and that pores in this size range are associated with higher enzymatic activity and thus higher $\mathrm{C}$ sequestration rates. However, these are cause-and-effect conclusions that are not supported by the data and research design that was implemented. The implications of this are that the study more clearly depicts effects of land use on various ecosystems and its association with soil microbial spatial footprints, rather than a direct causal relationship as stated by the authors.

First, Kravchenko et al. ${ }^{1}$ suggest that $30-150 \mu \mathrm{m}$ pores contain the most active microbial communities, resulting in higher rates of $\mathrm{C}$ processing and sequestration. However, this is only true for the monoculture systems and not for the two biodiverse ecosystems. The biodiverse native vegetation systems (poplar and native succession) were reported to contain the highest amount of $30-150 \mu \mathrm{m}$ pores, and thus would be expected to show the highest rates of enzyme activity. However, the data in Fig. 4a of Kravchenko et al. contradict this conclusion. Distribution of enzymatic activity surrounding $30-150 \mu \mathrm{m}$ pores is reported as less in the diverse native ecosystems than in the monoculture ecosystems. This represents a significant discrepancy between the data and the conclusions that were drawn.

Second, the authors also concluded that diverse plant communities favor development of $30-150 \mu \mathrm{m}$ pores. However, due to the use of a non-experimental design, such cause-and-effect conclusions cannot be drawn due to uncontrolled variables ${ }^{2,3}$. Specifically, the presence of these pores cannot be uniquely attributed to the heterogeneity of the plant communities. While root growth is indeed a method of pore development, there are other major factors affecting porosity in soil: the movement of water and biota through the matrix, organic matter and mineral content, depth of surface and subsurface horizons, chemical reactions, historical management practices, and more ${ }^{4}$. These properties may vary dramatically from one studied ecosystem to another, even among similar climates and topography. It would be necessary to determine the degrees of influence of each of these factors and more before a conclusion can be reached regarding the effect of plant community diversity on pore development. The whole-system processes and attributes are neither controlled nor measured by the authors, so only conclusions about associations and not effects are warranted. The study is a comparatively clearer look at the effects of land use on various ecosystems and its association with soil microbial spatial footprints.

A more limited replacement conclusion is proposed: "The factors of ecosystem biodiversity, microbial biomass, soil carbon partitioning, porosity, and extrapore enzymatic activity are all moderately associated with one other across ecosystems, with enzymatic activity level at its highest in the soil surrounding $30 \mu \mathrm{m}$ pores in poplar systems and $30-150 \mu \mathrm{m}$ pores in monocultures."

The study has many major strengths, including the technical feat of combining X-ray micro-tomography for pore mapping with enzyme spatial distribution mapping, a 9-year duration for the tracking of soil properties in five different systems, excellent sampling and methodology, advanced statistical analysis, and an experimental design for the fresh nutrient input incubation portion of the study. Nonetheless, for these reasons stated above, the primary conclusion that $30-150 \mu \mathrm{m}$ pores in diverse plant communities have a greater soil C storage capacity is not sufficiently supported to warrant adoption into soil conservation and regenerative agriculture approaches.

Reporting summary. Further information on research design is available in the Nature Research Reporting Summary linked to this article.

\section{Data availability}

Data sharing not applicable to this article as no datasets were generated or analyzed during the current study.

Received: 19 August 2019; Accepted: 2 November 2020; Published online: 22 December 2020 


\section{References}

1. Kravchenko, A. N. et al. Microbial spatial footprint as a driver of soil carbon stabilization. Nat. Commun. 10, 3121 (2019).

2. Drinkwater, L. E. Cropping systems research: reconsidering agricultural experimental approaches. HortTechnology 12, 355-361 (2002).

3. Mead, R., Curnow, R. N. \& Hasted, A. M. Statistical Methods in Agriculture and Experimental Biology. 3rd edn (Chapman and Hall/CRC Press, Boca Raton, FL, 2002).

4. Nimmo, J. R. Porosity and pore size distribution, reference module in earth systems and environmental sciences. Elsevier https://doi.org/10.1016/B978-012-409548-9.05265-9 (2013).

\section{Acknowledgements}

This research did not receive any specific grant from funding agencies in the public, commercial, or non-profit sectors.

\section{Author contributions}

The sole author of this manuscript conducted all of the work and analysis in the study.

\section{Competing interests}

The author declare no competing interests.

\section{Additional information}

Supplementary information is available for this paper at https://doi.org/10.1038/s41467020-19900-9.

Correspondence and requests for materials should be addressed to M.M.G.

Peer review information Nature Communications thanks Aimeric Blaud and the other, anonymous, reviewer(s) for their contribution to the peer review of this work.

Reprints and permission information is available at http://www.nature.com/reprints

Publisher's note Springer Nature remains neutral with regard to jurisdictional claims in published maps and institutional affiliations.

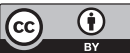
appropriate credit to the original author(s) and the source, provide a link to the Creative Commons license, and indicate if changes were made. The images or other third party material in this article are included in the article's Creative Commons license, unless indicated otherwise in a credit line to the material. If material is not included in the article's Creative Commons license and your intended use is not permitted by statutory regulation or exceeds the permitted use, you will need to obtain permission directly from the copyright holder. To view a copy of this license, visit http://creativecommons.org/ licenses/by/4.0/.

(C) The Author(s) 2020 